\title{
Antioxidant, Cytotoxic and Antibacterial Activity and Total Phenol Contents of the Roots and the Shoots of Euphorbia macrostegia and Euphorbia microsciadia
}

\author{
Somayeh Zare ${ }^{1,2}$, Niloofar Moheimanian ${ }^{1,2}$, Omidreza Firuzi ${ }^{1}$, Amir Reza Jassbi ${ }^{1 *}$ \\ ${ }^{1}$ Medicinal and Natural Products Chemistry Research Center, Shiraz University of Medical Sciences, Shiraz, Iran \\ ${ }^{2}$ Students Research Committee, Shiraz University of Medical Sciences, Shiraz, Iran
}

Received: 06/01/2020

Accepted: 13/04/2020

Published: 20/03/2021

\begin{abstract}
The roots and the shoots of Euphorbia macrostegia and E. microsciadia were extracted using different solvents; dichloromethane (DCM), methanol (MeOH) and $\mathrm{MeOH}$ : water (80:20) and the extracts were screened for their cytotoxic, antioxidant and antimicrobial properties as well as total phenolic content. Cytotoxicity of the extracts was evaluated against human acute lymphoblastic leukemia (MOLT-4) cells by MTT reduction assay. The extracts were also subjected to the 2,2'-diphenyl-1-picrylhydrazyl (DPPH) free radical scavenging and Folin-Ciocalteu total phenolic assays. The MeOH extract of the shoots of E. microsciadia and DCM extract of the roots of $E$. macrostegia were the most cytotoxic ones with $\mathrm{IC}_{50}$ values of $10.5 \pm 2.6$ and $7.0 \pm 1.2 \mu \mathrm{g} / \mathrm{mL}$, respectively. The MeOH extract of the shoots of E. microsciadia showed considerable antioxidant activity $\left(\mathrm{IC}_{50}=9.95 \pm 1.00 \mu \mathrm{g}\right.$ plant extracted to scavenge $1 \mathrm{~mL}$ of a 0.1 $\mathrm{mM}$ DPPH solution), which was consistent with its highest phenolic content $(288.50 \pm 29.38 \mathrm{mg}$ equivalent of gallic acid in $1 \mathrm{~g}$ dry plant extract: mg EG/g PE). Determination of minimum inhibitory concentrations (MICs) using the broth dilution method, confirmed that all the extracts from the plants gave various degrees of antibacterial activity against all tested microorganisms. In thin layer chromatography (TLC) investigations, some compounds previously isolated from Euphorbia species inclduing cycloartenol, 24-methylenecycloartan-3 $\beta$ $\mathrm{ol}, \beta$-sitosterol and euphol were tested and suggested to be responsible for the above-mentioned biological activities in the plants. Therefore, we suggest E. macrostegia and especially E. microsciadia as new sources for isolation and identification of various bioactive compounds.
\end{abstract}

Keywords: Euphorbia microsciadia, Euphorbia macrostegia, anticancer effect, biological activity, radical scavenging, natural compounds and phytochemical analyses

\section{Introduction}

Euphorbia is the largest genus of the family Euphorbiaceae (spurges), with more than 2000 known species and is characterized by the presence of milky latex and unique flower structures. It has about 80 species in Iran, two of which are called locally "Dena and Persian spurge", E. microsciadia Boiss. and E. macrostegia Boiss., respectively. They grow in the mountainous area of Iran $(1,2)$. Various species of the genus Euphorbia have shown different biological activities including enzyme inhibition and cytotoxic activity (3). In addition to their biological activities, these plants are ecologically important in the flora of Iran as weeds, antivegetative and poisonous plants (2).

It has been previously shown that a butanol/hexane extract of the aerial parts of E. microsciadia had the ability to modulate T-cell responses that suggest its possible beneficial effect on immune host defense (4). A MeOH extract of E. microsciadia showed stimulatory effects on the proliferation of the lymphocytes and a $n$-hexane layer of the $\mathrm{MeOH}$ extract had significant strong antiproliferative effect against tumor cells (5). The immunosuppressive activity of the plant's extract was attributed to the presences of quercetin-3- $\beta-O$ galactopyranoside, while myricetin-3- $\beta$ - $O$-galactopyranoside was less active constituent among the isolated flavonol glycosides from the aerial part of the plant (6). On the other hand, a dichloromethane (DCM) extract of E. macrostegia showed cytotoxicity against two cancer cell lines; MDA-MB48 and MCF-7 (7). Four cycloartane triterpenoids were isolated from the DCM extract. Two of which; cycloart-23(E)-ene$3 \beta, 25$-diol and cycloart-23(Z)-ene-3 $\beta, 25$-diol, showed the strongest cytotoxicity against the above mentioned cell lines, respectively. In addition to the cytotoxic activity, the tyrosinase inhibitory activity of constituents of E. macrostegia has also been reported recently (8). Among 10 compounds identified in the plants' extract, 2-(4-hydroxyphenyl)ethylhentriacontanoate, hentriacontan-1-ol, lupenone and cycloart-22-ene-3,25-diol were detected as the most active tyrosinase inhibitors with $\mathrm{IC}_{50}$ of $71.4-78.6 \mu \mathrm{M}$. Also, recently we isolated three triterpenoids; 24-methylenecycloartan-3 $\beta$-ol, butyrospermol and cycloartenol and three diglycerides, 1,2-diO- $\alpha$-linolenoyl-sn-glycerol, 1-O-linoleoyl-3- O-palmitoyl-snglycerol and 1-O- $\alpha$-linolenoyl-2-O-palmitoyl-sn-glycerol from

Corresponding Author: Amir Reza Jassbi: Medicinal and Natural Products Chemistry Research Center, Shiraz University of Medical Sciences, Shiraz, Iran. Tel: +98-71-32303872, E-mail: jassbiar@sums.ac.ir 
the hexane soluble part of $\mathrm{MeOH} / \mathrm{DCM}$ extracts of $E$. macrostegia Boiss. (9).

In this study, we report here antimicrobial potential, DPPH radical scavenging activity, total phenolic contents and cytotoxicity of different extracts of the roots and shoots of $E$. macrostegia and E. microsciadia.

\section{Materials and Methods}

\subsection{General Experimental Procedures}

RPMI 1640 (cell culture medium), fetal bovine serum (FBS), trypsin, and phosphate buffered saline (PBS) were purchased from Biosera (Ringmer, UK). Chloramphenicol and 3-(4,5-Dimethylthiazol-2-yl) -2,5-diphenyltetrazolium bromide (MTT) were obtained from Sigma-Aldrich (St Louis, MO, USA) and penicillin/streptomycin were purchased from Invitrogen (San Diego, CA, USA). Doxorubicin and FolinCiocalteu reagents were obtained from EBEWE Pharma (Unterach, Austria) and Fluka, respectively. 2,2'-diphenyl-1picrylhydrazyl (DPPH), Vanillin and p-iodonitrotetrazolium violet (INT) were purchased from Merck chemical companies. All the solvents were purchased from Merck. Thymol was purchased from Riedel-de Haen (Germany).

\subsection{Plant material}

Euphorbia microsciadia Boiss. and Euphorbia macrostegia Boiss. were collected in July 2012 from the Dena mountain (N 30 $52^{\prime}$ E 51 $31^{\prime}, 2980 \mathrm{~m}$ altitude), Yasuj, Iran. The plants were identified by Mr. Mehdi Zare and Dr. Mojtaba Asadollahi, plant taxonomists, in Medicinal and Natural Products Chemistry Research Center (MNCRC), Shiraz University of Medical Sciences, Iran. A voucher specimen for E. macrostegia (PC-91-4-1-1.2) and E. microsciadia (PC-914-2-1.2) has been deposited in the herbarium of MNCRC.

\subsection{Extraction procedure}

The shade-dried powdered shoots and roots of $E$. microsciadia $(120 \mathrm{~g})$ and E. macrostegia $(120 \mathrm{~g})$ were extracted twice separately and sequentially in $1500 \mathrm{~mL}$ of $\mathrm{DCM}, \mathrm{MeOH}$ and $80 \% \mathrm{MeOH}$, by maceration for $24 \mathrm{~h}$. at room temperature. Each filtered extract was concentrated to remove traces of the solvents under reduced pressure using a rotary evaporator to afford the respective dried solvent extracts. The weight of the shoots and the roots extracts of the plants were respectively as follows: DCM (1.04 and $5.8 \mathrm{~g}), \mathrm{MeOH}(12.4$ and $4.2 \mathrm{~g}$ ), and $80 \% \mathrm{MeOH}(4.16$ and $1.44 \mathrm{~g}$ ) for $E$. microsciadia and DCM (2.4 and $1.44 \mathrm{~g}), \mathrm{MeOH}(0.8$ and 2.8 $\mathrm{g}$ ), and $80 \% \mathrm{MeOH}$ (4.08 and $1.04 \mathrm{~g}$ ) for E. macrostegia.

\subsection{Preparation of the extracts, pure compounds, and TLC conditions}

The dried $\mathrm{MeOH}$ and $80 \% \mathrm{MeOH}$ extracts were dissolved in $\mathrm{MeOH}$ to a concentration of $5 \mathrm{mg} / \mathrm{mL}$ for TLC analysis. Also for the bioassays, the extracts were prepared in their extracting solvents in different concentrations. Pure phytochemicals, previously isolated from Euphorbia plants in our group, named cycloartenol (1), 24-methylenecycloartan-3 $\beta$-ol (2), $\beta$ sitosterol (3) and euphol (4), were selected for the assessment of their existence in the above extracts (Figure 1). They were extracted from the hexane soluble part of methanoldichloromethane extracts of the aerial parts of E. macrostegia (1 and 2) (9), methanol-dichloromethane extracts of $E$. erythradenia (3) (10), and acetone extract of the roots of $E$. microsciadia (4) (11). They were dissolved in $\mathrm{MeOH}$ (5 $\mathrm{mg} / \mathrm{mL}$ ) for spotting on TLC plates. We analyzed the chemical constituents of the extracts compared to the standard phytochemicals 1-4 using pre-coated TLC plates (silica gel 60 F254, $0.25 \mathrm{~mm}$ film thickness, Merck). Different composition of mobile phase were examined to obtain optimum retention factor $\left(\mathrm{R}_{\mathrm{f}}\right)$ and resolution. In addition, two TLC reagents thymol-sulfuric acid $(0.5 \mathrm{~g}$ thymol in $95 \mathrm{~mL}$ EtOH and $5 \mathrm{~mL}$ $\left.97 \% \mathrm{H}_{2} \mathrm{SO}_{4}\right)$ and vanillin-sulfuric acid $(0.3 \mathrm{~g}$ vanillin: $28 \mathrm{ml}$ ethanol: $1 \mathrm{ml}$ sulfuric acid), were sprayed followed by heating the developed TLCs to distinguish different phytochemical classes such as glycosides and terpenes in different colors (12).
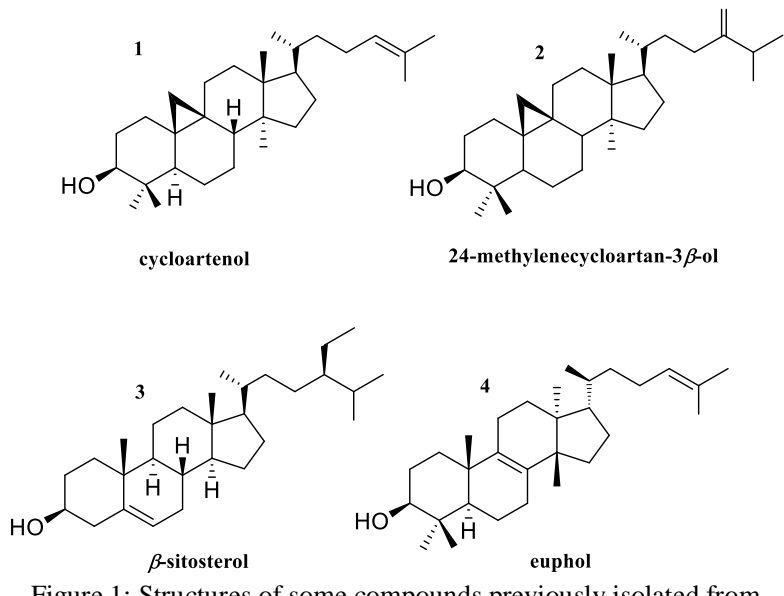

Figure 1: Structures of some compounds previously isolated from Euphorbia plants

\subsection{Cytotoxic bioassay}

Human acute lymphoblastic leukemia (MOLT-4) cells were obtained from the National Cell Bank of Iran, Pasteur Institute, Tehran, Iran. MTT assay was performed to assess viability after the exposure of cells to the extracts $(13,14)$. The cells were cultured in RPMI 1640 medium supplemented with 100 units $/ \mathrm{mL}$ penicillin-G, $10 \%$ FBS, and $100 \mu \mathrm{g} / \mathrm{mL}$ streptomycin and maintained at $37^{\circ} \mathrm{C}$ in humidified air containing $5 \% \mathrm{CO}_{2}$. The experiments were performed in 96well microplates and 3000 cells were seeded in each well. The wells containing growth medium alone were used as blank for background correction. After overnight incubation at $37^{\circ} \mathrm{C}$, half of the growth medium was removed and medium supplemented with different concentrations of extracts were added in triplicate. The extracts of E. microsciadia and $E$. macrostegia were first dissolved in DMSO and then diluted several times in complete growth medium. Maximum concentration of DMSO in the wells did not exceed $0.5 \%$, a concentration that showed no cytotoxicity in the cells. Standard cytotoxic agents; cisplatin and doxorubicin were used as positive controls. After incubation for further $72 \mathrm{~h}$, the medium was removed and MTT was added to each well at a final concentration of $0.5 \mathrm{mg} / \mathrm{mL}$ and plates were incubated for another $4 \mathrm{~h}$ at $37^{\circ} \mathrm{C}$. In the end, formazan crystals were dissolved in $200 \mu \mathrm{l}$ DMSO. The optical density was evaluated at $570 \mathrm{~nm}$ using a microplate reader (Bio-Rad, Model 680) with background correction at $655 \mathrm{~nm}$. The percentage of viability compared to control wells was calculated for each concentration of the extracts and $\mathrm{IC}_{50}$ values were estimated with the software Curve Expert (for Windows, version 1.34). Each experiment was repeated at least 3 times and data were presented as mean \pm S.E.M.

\subsection{DPPH radical scavenging activity}

The antioxidant activities of all extracts of E. microsciadia and $E$. macrostegia were determined according to the modified method that we have previously described $(9,15-17)$. Briefly, $5 \mu \mathrm{L}$ of the extracts was mixed with $195 \mu \mathrm{L}$ of $0.1 \mathrm{mM}$ DPPH in 96-well microplate. After incubation in the dark at room temperature for 30 minutes, the absorbance of the reaction 
mixture was measured at $\lambda 517 \mathrm{~nm}$ using a Bio-Rad microplate reader. Inhibition ratio (percent) was calculated from the following equation:

DPPH radical scavenging activity $(\%)=\left[\left(\right.\right.$ Abscontrol $^{-}$Abssample $)$ / AbsControl] $\times 100$

We used butylated hydroxytoluene (BHT) and quercetin as the standards radical scavenger. The $\mathrm{IC}_{50}$ values were calculated by linear regression equations of the DPPH inhibition percentage from different concentrations of the extracts and the standards, using Microsoft Excel and Curve Expert statistical programs (15).

\subsection{Determination of total phenolic content}

The concentration of total phenolics in the DCM, MeOH and $80 \% \mathrm{MeOH}$ extracts were determined separately by the Folin-Ciocalteu colorimetric method as described previously (18). Briefly, in each test plate, $5 \mu \mathrm{L}$ of the $10 \mathrm{mg} / \mathrm{mL}$ plant extracts or the standard gallic acid solution, $158 \mu \mathrm{L}$ distilled water and $10 \mu \mathrm{L}$ Folin-Ciocalteu reagent were added and the solution was shaken briefly on a vortex mixer well, then after 8.5 min incubation at room temperature $30 \mu \mathrm{L}$ of a $0.25 \%$ sodium carbonate was added to each solution. The reaction mixtures were kept in the dark at room temperature for $2 \mathrm{~h}$ and the absorbance of the solutions were measured at $\lambda 765 \mathrm{~nm}$ against the blank. The concentrations of the total phenolics were measured against a series of gallic acid standard solutions and expressed as $\mathrm{mg}$ equivalent of gallic acid in $1 \mathrm{~g}$ plant extract (mg EG/g PE) (18).

\subsection{Antibacterial minimum inhibitory concentration using nutrient broth microdilution}

To examine the antibacterial activity of the plant extracts, four Gram-negative bacteria (Escherichia coli: PTCC1330, Klebsiella pneumoniae: PTCC1053, Pseudomonas aeruginosa: PTCC 1074, and Salmonella typhi: PTCC1609) and three Gram-positive bacteria (Staphylococcus aureus: PTCC1112, Staphylococcus epidermidis: PTCC1114, Bacillus subtilis: PTCC1023) were chosen to measure the minimum inhibitory concentrations (MIC) of the active extracts using nutrient broth micro-dilution (NBMD) assays (19). To perform the test, the stock solution of plant extracts were serially diluted in dimethyl sulfoxide (DMSO) to afford different concentrations of test samples. Chloramphenicol solution in DMSO was also prepared as the positive control. Breifly, $5 \mu \mathrm{L}$ of the tests sample solutions was added to $95 \mu \mathrm{L}$ of the fresh media and $100 \mu \mathrm{L}$ of bacterial suspension culture $(\mathrm{OD}=0.1$ at $600 \mathrm{~nm})$ in a 96-well microplate. After $24 \mathrm{~h}$ incubation at $37{ }^{\circ} \mathrm{C}$ in a shaking incubator, $10 \mu \mathrm{L}$ of a $0.5 \%$ INT solution in water was added to each well. Afterwards, at the above-mentioned culture conditions, the microplates were incubated for further $30 \mathrm{~min}$. Finally, the MIC was calculated as the minimum concentration of the test sample extract or antibacterial standard inhibiting the growth of bacterial strain by discoloration of the purple INT solution (6).

\section{Results and Discussion}

Cytotoxicity of DCM, MeOH and $80 \% \mathrm{MeOH}$ extracts of the roots and shoots of E. macrostegia and E. microsciadia were tested against MOLT-4 cells (Table 1). Among the tested extracts of E. microsciadia, the DCM extracts showed no activity. The $\mathrm{MeOH}$ and $80 \% \mathrm{MeOH}$ extracts of the shoots of this plant with $\mathrm{IC}_{50}$ values of $10.5 \pm 2.6$ and $17.1 \pm 2.9 \mu \mathrm{g} / \mathrm{mL}$, respectively, showed stronger activity compared to the same extracts from the roots with the $\mathrm{IC}_{50}$ values of $46.0 \pm 3.5$ and $40.0 \pm 3.7 \mu \mathrm{g} / \mathrm{mL}$, respectively. Unlike E. microsciadia, all the three extracts of $E$. macrostegia showed strong activity against MOLT-4 cells with IC 50 values in the range of $7.0-38.4 \mu \mathrm{g} / \mathrm{mL}$. Unlike E. microsciadia, the root extracts of E. macrostegia exhibited lower $\mathrm{IC}_{50}$ s compared to the extracts from the shoots of this plant.

The $\mathrm{MeOH}$ and $80 \% \mathrm{MeOH}$ extracts of the shoots of $E$. microsciadia showed the highest radical scavenging potentials in the DPPH free-radical test, with $\mathrm{IC}_{50}$ values of $9.95 \pm 1.00$ and $10.82 \pm 1.64 \mu \mathrm{g} / \mathrm{mL}$, respectively (Table 2 ). Their activities are more than that measured for butylated hydroxytoluene (BHT: $\mathrm{IC}_{50}=51.09 \pm 1.35 \mu \mathrm{g} / \mathrm{mL}, \mathrm{P}<0.05$ ) but less than the quercetin's radical scavenging potential with an $\mathrm{IC}_{50}$ value of $2.0 \pm 0.16 \mu \mathrm{g} / \mathrm{mL}(\mathrm{P}<0.05)$. The other extracts exhibited radical scavenging activity in the range of $28.51-85.22 \mu \mathrm{g} / \mathrm{mL}$.

Table 1: Cytotoxic activity of different extracts of E. macrostegia and E. microsciadia

\begin{tabular}{llll}
\hline \multicolumn{1}{c}{ Sample name } & $\begin{array}{l}\text { MOLT-4 IC50 }(\boldsymbol{\mu g} / \mathbf{m L}) \\
(\text { MeOH extract) }\end{array}$ & $\begin{array}{l}\text { MOLT-4 IC50 }(\boldsymbol{\mu g} / \mathbf{m L}) \\
(\mathbf{8 0 \%} \text { MeOH extract) }\end{array}$ & $\begin{array}{l}\text { MOLT-4 IC50 }(\boldsymbol{\mu g} / \mathbf{m L}) \\
(\text { DCM extract) }\end{array}$ \\
\hline E. macrostegia, shoots & $34.1 \pm 4.2$ & $38.4 \pm 3.2$ & $13.4 \pm 2.3$ \\
E. macrostegia, roots & $7.9 \pm 1.0$ & $34.8 \pm 3.3$ & $7.0 \pm 1.2$ \\
E. microsciadia, shoots & $10.5 \pm 2.6$ & $17.1 \pm 2.9$ & - \\
E. microsciadia, roots & $46.0 \pm 3.5$ & $40.0 \pm 3.7(11)$ & $>100$ \\
Doxorubicin $(\mathbf{n M})$ & $17.2 \pm 2.0$ & - & - \\
Cisplatin $(\boldsymbol{\mu M})$ & $3.1 \pm 0.7$ & - & - \\
\hline
\end{tabular}

Table 2: DPPH radical scavenging activity and total phenolic contents (mg EG/g PE) of different extracts of E. macrostegia and E.

\begin{tabular}{|c|c|c|c|c|}
\hline Sample name & $\begin{array}{l}\text { DPPH IC } \text { I0 }_{50}(\mu \mathrm{g} / \mathrm{mL}) \\
(\text { MeOH extract) }\end{array}$ & $\begin{array}{l}\text { Total phenol } \\
\text { (MeOH extract) }\end{array}$ & $\begin{array}{l}\text { DPPH IC } \text { I0 }_{50}(\mu \mathrm{g} / \mathrm{mL}) \\
(80 \% \mathrm{MeOH} \text { extract })\end{array}$ & $\begin{array}{l}\text { Total phenol }(80 \% \\
\text { MeOH extract) }\end{array}$ \\
\hline E. macrostegia, shoots & $47.64 \pm 4.74$ & $78.94 \pm 3.89$ & $28.51 \pm 2.37$ & $147.12 \pm 5.46$ \\
\hline E. macrostegia, roots & $41.68 \pm 2.97$ & $71.65 \pm 1.01$ & $35.55 \pm 3.14$ & $132.53 \pm 4.43$ \\
\hline E. microsciadia, shoots & $9.95 \pm 1.00$ & $288.50 \pm 29.38$ & $10.82 \pm 1.64$ & $203.61 \pm 28.58$ \\
\hline E. microsciadia, roots & $45.39 \pm 2.93(20)$ & $37.59 \pm 2.07$ & $85.22 \pm 2.98$ & $18.29 \pm 1.45$ \\
\hline BHT & $51.09 \pm 1.35$ & - & $51.09 \pm 1.35$ & - \\
\hline Quercetin & $2 \pm 0.16$ & - & $2 \pm 0.16$ & - \\
\hline
\end{tabular}


Table 3: Minimum inhibitory concentrations $(\mathrm{mg} / \mathrm{mL})$ of different extracts of E. macrostegia and E. microsciadia by nutrient-broth micro-dilution bioassay

\begin{tabular}{|c|c|c|c|c|c|c|c|}
\hline $\begin{array}{l}\text { Microorganisms (rows) } \\
\text { Plants }\end{array}$ & S.a. & S.e. & B.s. & S.t. & P.a. & E.c. & K.p. \\
\hline E. macrostegia, shoots (DCM extract) & NA & NA & 1.25 & NA & NA & 1.25 & 1.25 \\
\hline E. macrostegia, shoots (MeOH extract) & 5 & 1.25 & 1.25 & 1.25 & 5 & 2.5 & 2.5 \\
\hline E. macrostegia, shoots ( $80 \%$ MeOH extract) & 1.25 & 1.25 & 5 & 1.25 & 5 & NA & NA \\
\hline E. macrostegia, roots (DCM extract) & NA & NA & 1.25 & NA & NA & 1.25 & 1.25 \\
\hline E. macrostegia, roots (MeOH extract) & 2.5 & 2.5 & 1.25 & 5 & 5 & 5 & 5 \\
\hline E. macrostegia, roots $(80 \% \mathrm{MeOH}$ extract) & 5 & 1.25 & 2.5 & 2.5 & 5 & 1.25 & 2.5 \\
\hline E. microsciadia, roots (DCM extract) & NA & NA & 1.25 & 5 & 5 & 5 & 5 \\
\hline E. microsciadia, roots (MeOH extract) & 5 & 1.25 & 1.25 & 2.5 & 2.5 & 1.25 & 1.25 \\
\hline E. microsciadia, roots ( $80 \% \mathrm{MeOH}$ extract) & 2.5 & 1.25 & 1.25 & 1.25 & 2.5 & 2.5 & 2.5 \\
\hline E. microsciadia, shoots (DCM extract) & 5 & 5 & 5 & 2.5 & NA & NA & 5 \\
\hline E. microsciadia, shoots (MeOH extract) & 5 & 2.5 & 5 & NA & NA & NA & 2.5 \\
\hline E. microsciadia, shoots (80\% MeOH extract) & 5 & 5 & 5 & 2.5 & NA & NA & 2.5 \\
\hline Chloramphenicol & 0.0125 & 0.025 & 0.0125 & 0.05 & 0.05 & 0.05 & 0.05 \\
\hline
\end{tabular}

NA: not active (>5). S.a., Staphylococcus aureus; S.e., Staphylococcus epidermidis; B.s., Bacillus subtilis; S.t., Salmonella typhi; P.a., Pseudomonas aeruginosa; E.c., Escherichia coli; K.p., klebsiella pneumoniae

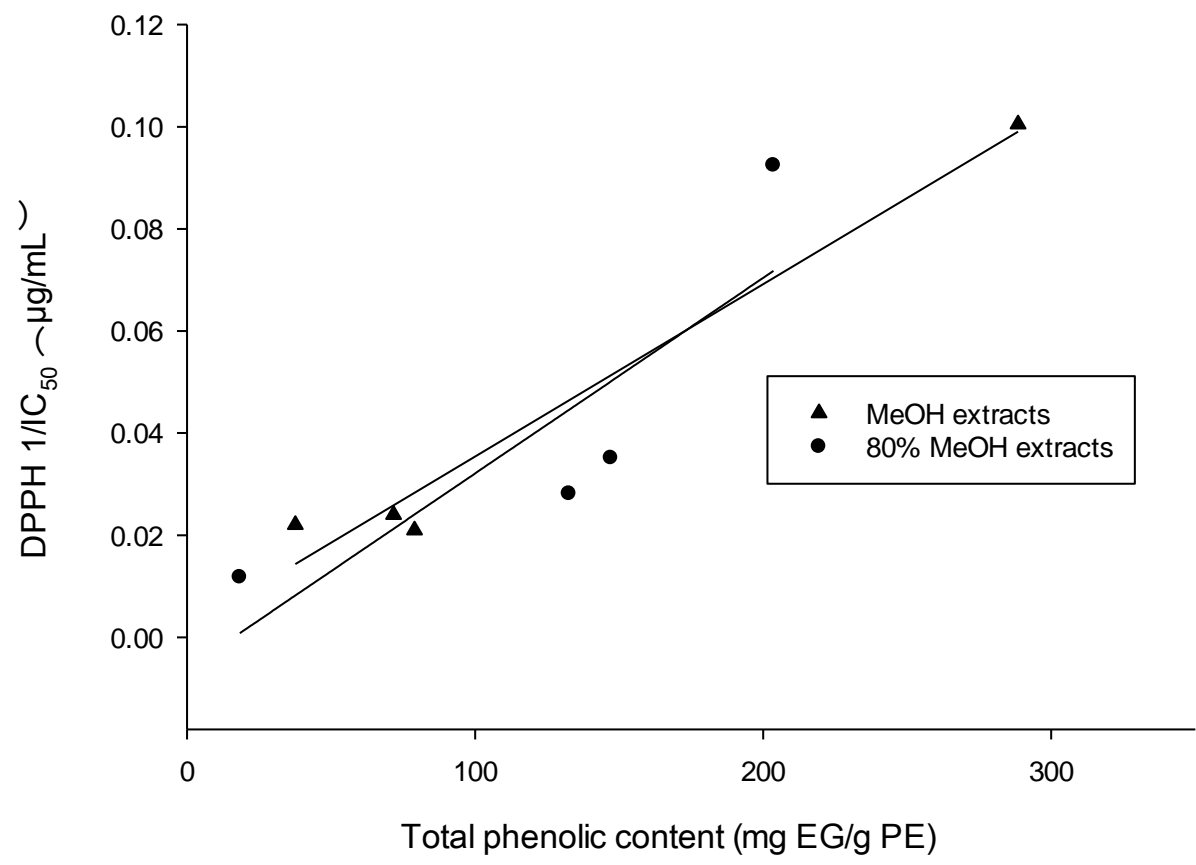

Figure 2: Correlation graphs for DPPH $1 / \mathrm{IC}_{50}$ values and total phenolic contents for $\mathrm{MeOH}$ and $80 \% \mathrm{MeOH}$ extracts

The $80 \% \mathrm{MeOH}$ extract of the roots of E. microsciadia had the weakest antioxidant activity against DPPH radicals, as the result of the highest $\mathrm{IC}_{50}$ value $(85.22 \pm 2.98 \mu \mathrm{g} / \mathrm{ml})$. The increasing order of total phenol contents $(18.29 \pm 1.45$ to $288.50 \pm 29.38 \mathrm{mg} \mathrm{EG} / \mathrm{g} \mathrm{PE})$ of the plant extracts were in agreement with the decreasing order of the $\mathrm{IC}_{50}(85.22 \pm 2.98$ to $9.95 \pm 1.00 \mu \mathrm{g} / \mathrm{mL}$ ) of DPPH test (Figure 2). The most prominent total phenolic contents was measured in the shoots of E. microsciadia, while the roots of E. microsciadia had the least TP contents. Antimicrobial activity of the DCM, $\mathrm{MeOH}$ and $80 \% \mathrm{MeOH}$ extracts of the plants were measured against four different Gram-negative and three Gram-positive bacteria (Table 3). The $\mathrm{MeOH}$ extracts of the shoots and roots of $E$. macrostegia, and methanol and $80 \% \mathrm{MeOH}$ extracts of the roots of E. microsciadia, were the most active antibacterial extracts that inhibited the growth of all tested microorganisms at MIC values between $1.25-5 \mathrm{mg} / \mathrm{mL}$ (Table 3). In addition,
DCM extract of E. macrostegia was only active at MIC 1.25 $\mathrm{mg} / \mathrm{mL}$ against the growth of B. subtilis, E. coli, and $K$. pneumonia. Generally, among the microorganisms, B. subtillis was the most susceptible ones to almost all extracts.

We have analyzed the bioactive plant extracts using TLC in comparison to Euphorbia derived phytochemicals. The TLC analyses of DCM, $\mathrm{MeOH}$ and $80 \% \mathrm{MeOH}$ of the roots and the shoots of E. macrostegia and E. microsciadia, resulted in several purple colored spots after vanillin-sulfuric acid reagent treatments after development by chloroform: acetone (95:5) mobile phase (Figure 3 ). Two spots with $\mathrm{R}_{\mathrm{f}}$ values between 0.45 and 0.80 , were present in all extracts, while the chromatogram of the methanol roots extract of E. macrostegia was the most chemically diverse among them. On the other hand, all of the tested extracts were analyzed by silica-gel TLC using more polar mobile phase (chloroform: formic acid: methanol: water $(5: 0.2: 3: 0.5))$. 


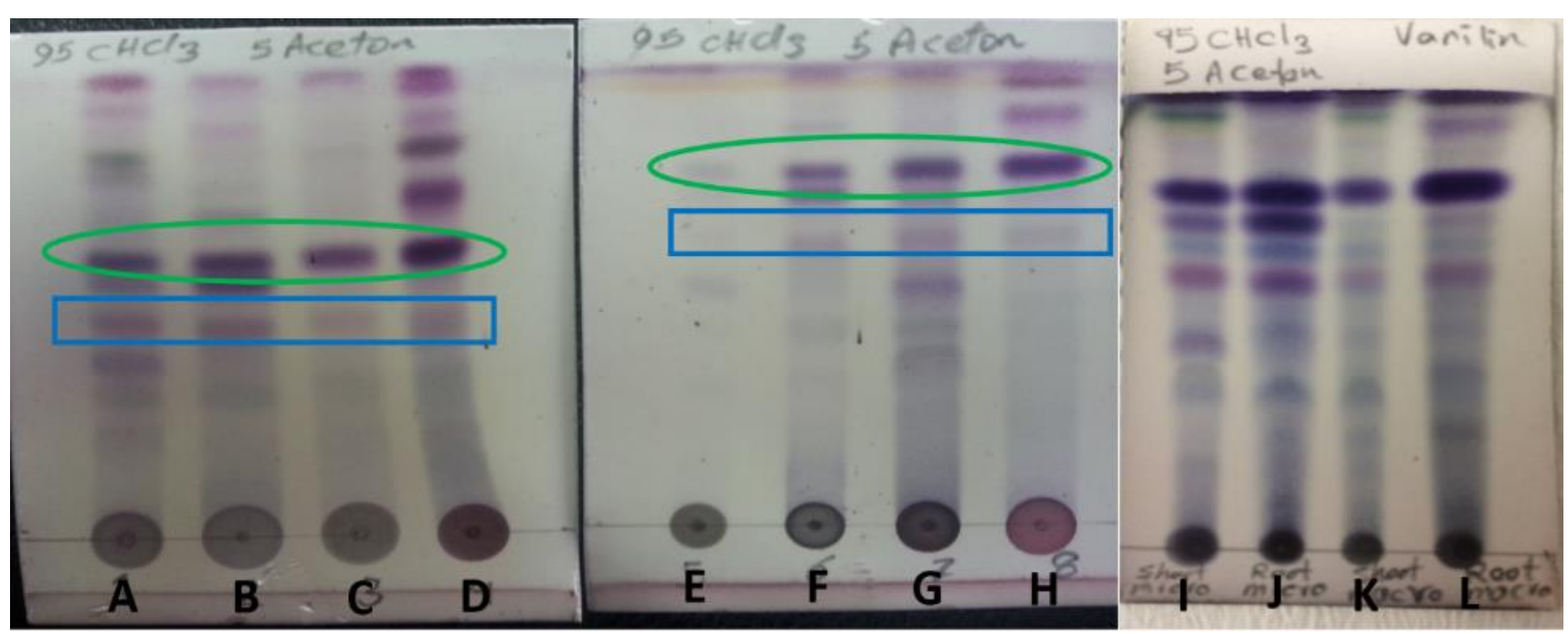

Figure 3: Spots in daylight after spray with vanillin-sulfuric acid using silica gel- TLC plates and chloroform: acetone (95:5) mobile phase. Spots are the $\mathrm{MeOH}$ extracts of the shoots (A) and the roots (B) of E. microsciadia, the $\mathrm{MeOH}$ extracts of the shoots (C) and the roots (D) of E. macrostegia, the $80 \%$ $\mathrm{MeOH}$ extracts of the shoots (E) and the roots (F) of E. microsciadia, the $80 \% \mathrm{MeOH}$ extracts of the shoots (G) and the roots (H) of E. macrostegia, DCM extracts of the shoots (I) and the roots (J) of E. microsciadia, and DCM extracts of the shoots (K) and the roots (L) of E. microsciadia

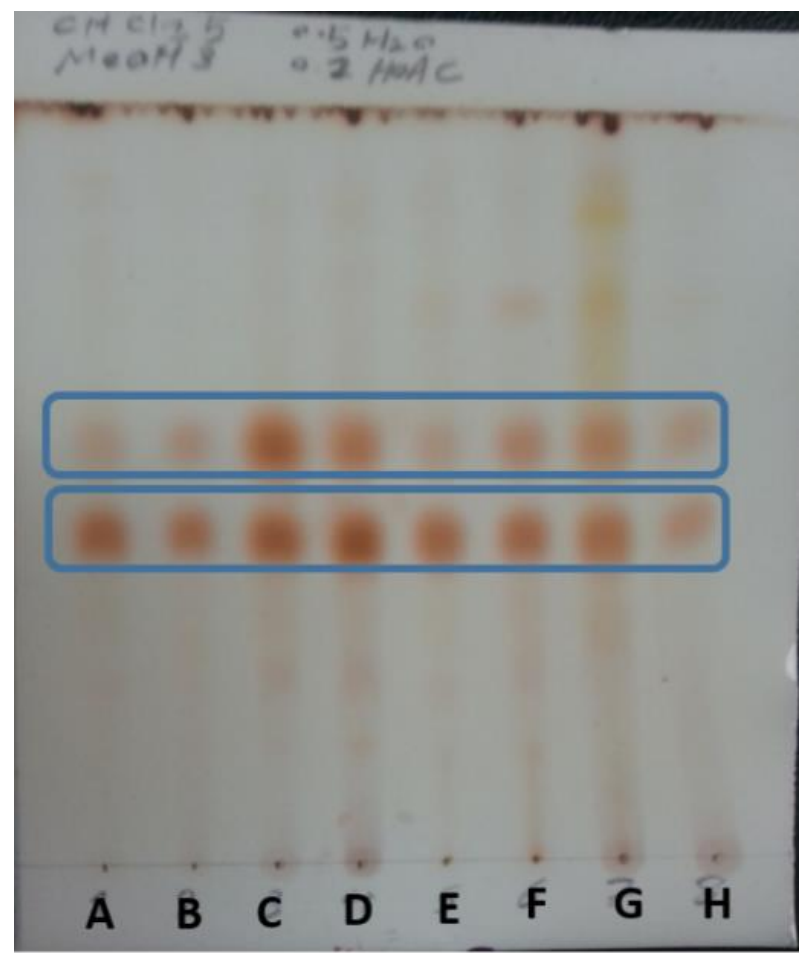

Figure 4: Spots in daylight after spray with thymol using a TLC plate and chloroform: formic acid: methanol: water (5:0.2:3:0.5). The extracts numbers are the same as described in Figure 3

Then, after visualizing the chromatogram by thymol spray reagent followed by heating, all the TLCs except DCM one, exhibited two major pink colored spots that suggested the glycosides character of compounds (Figure 4). While, the pink colored compounds were appeared as green-gray color spots (except the $80 \%$ extracts of roots and shoots of E. macrostegia) when the chromatogram sprayed with vanillin-sulfuric acid reagent (Figure 5). Co-TLC analyses of the extracts along with common phytochemicals $\mathbf{1}, \mathbf{2}, \mathbf{3}$ and $\mathbf{4}$ were performed using silica gel (Figure 6, (1)) and $\mathrm{AgNO}_{3}$ - silica gel stationary phases (Figure 6, (2), (3)). In literature, compound 1 and 4 showed antioxidant and cytotoxic activity, while compound $\mathbf{3}$ showed antibacterial activity (20-24). Compounds $\mathbf{1}$ and $\mathbf{2}$ are present in almost all extracts in different ratios (Figure 6 (1), (3)), while the presence of compound $\mathbf{3}$ was confirmed in the $\mathrm{MeOH}$ extracts of the shoots of E. microsciadia, the roots of $E$. macrostegia, $80 \% \mathrm{MeOH}$ extracts of the roots of $E$. microsciadia and the shoots of E. macrostegia and all the DCM extracts. To distinguish compounds $\mathbf{1}$ and $\mathbf{2}$, we used silica gel TLC plates impregnated with $5 \% \mathrm{AgNO}_{3}$, using chloroform: acetone (97:3) as the mobile phase, followed by treatment with the thymol-sulfuric acid reagent spray. In $\mathrm{AgNO}_{3}$-silica gel TLC plate, compound $\mathbf{1}$ is clearly present in all $\mathrm{MeOH}$ and $80 \%$ $\mathrm{MeOH}$ extracts of the roots of the plants (Figure 6, (2)).

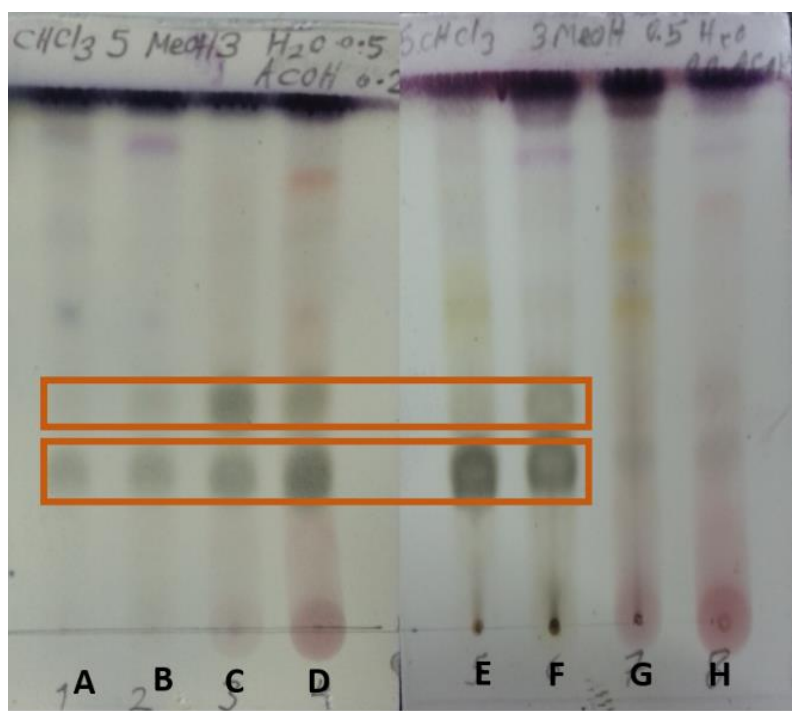

Figure 5: Spots in daylight after spray with vanillin-sulfuric acid reagent using an TLC plate and chloroform: formic acid:methanol:water (5:0.2:3:0.5). The extract numbers are the same as described in Figure 3 


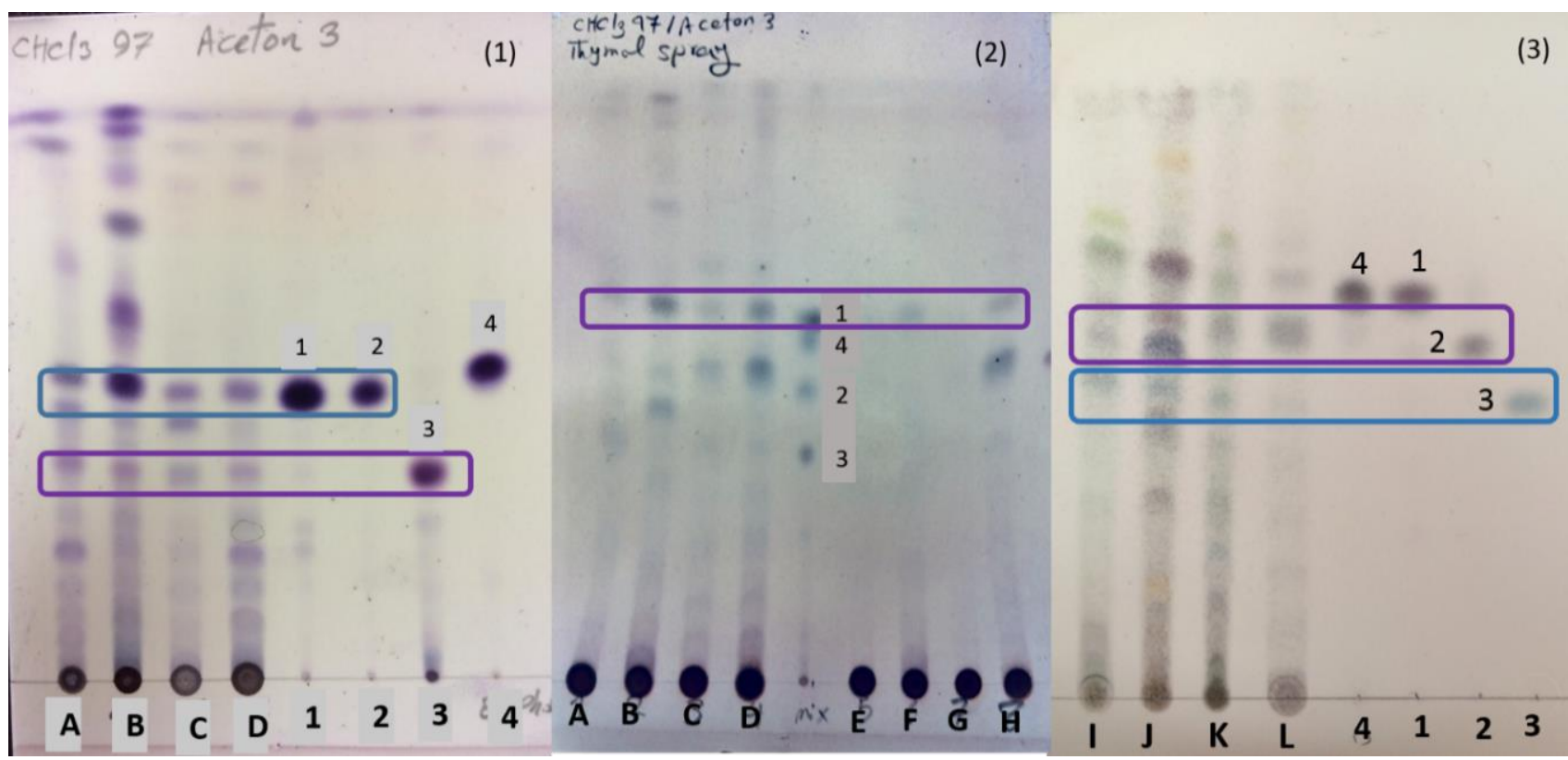

Figure 6: (1) Spots in daylight using chloroform: acetone (97:3) as the mobile phase (left) spray with vanillin-sulfuric acid reagent using an TLC plate, (2) and (3) spray with thymol reagent using $\mathrm{AgNO}_{3}$ coated TLC plate. cycloartenol [1] 24-methylenecycloartan-3 $\beta$-ol [2], $\beta$-sitosterol [3] and euphol [4]. The extract numbers are the same as described in Figure 3

\section{Conclusion}

The $\mathrm{MeOH}$ and DCM extracts of the roots of $E$. macrostegia are good candidates to isolate cytotoxic compounds. While the shoots DCM, and $80 \% \mathrm{MeOH}$ extracts of the plant are suitable for extraction of cytotoxic and radical scavengers. However, the shoots of E. microsciadia is the best for exploring cytotoxic, and antioxidants when the plant is extracted with $\mathrm{MeOH}$ and $80 \% \mathrm{MeOH}$. The shoots $\mathrm{MeOH}$ extracts and roots $\mathrm{MeOH}$ and $80 \% \mathrm{MeOH}$ extracts of $E$. macrostegia are the best for exploring antibacterial agents, while the last two solvent extracts of E. microsciadia shoots are preferred for isolating moderate antibacterial agents. The above-mentioned results indicated that the semi-polar to polar substances are responsible for the studied biological activity of the shoots of E. microsciadia in addition to the nonpolar to polar phytochemicals in both roots and shoots of $E$. macrostegia. It seems that terpenoid and glycosylated phytochemicals are the major phytochemicals in the DCM, $\mathrm{MeOH}$ and $80 \% \mathrm{MeOH}$ extracts of E. macrostegia and E. microsciadia, which need to be isolated and identified. The antibacterial, cytotoxic and antioxidant activity of the plant extracts may be attributed to the presence of compounds 1-4 as these activities have been reported for them previously in the literature. For instance, compound $\mathbf{1}$ and $\mathbf{4}$ showed antioxidant and cytotoxic activity, while compound $\mathbf{3}$ showed antibacterial activity $(12,14,19,21,22)$. However, the other compounds detected in the TLCs maybe isolated, identified, and further tested for the above biological activities in future.

\section{Acknowledgements}

We are grateful to Mr. Mehdi Zare and Dr. Mojtaba Asadollahi for collection and identification of the plant material and the research council of Shiraz University of Medical Sciences for financial support of this project.

\section{Competing interests}

The authors declare that there is no conflict of interest that would prejudice the impartiality of this scientific work.

\section{Authors' contribution}

All authors of this study have a complete contribution for data collection, data analyses and manuscript writing.

\section{References}

1. Mozaffarian V. A Dictionary of Iranian Plant Names: Latin, English, Persian. Farhang Mo'aser, Tehran. 2003.

2. Pahlevani AH. Notes on some species of the genus Euphorbia in Iran. Rostaniha. 2007 8(2):89-103.

3. Jassbi AR. Chemistry and biological activity of secondary metabolites in Euphorbia from Iran. Phytochemistry. 2006 67(18):1977-84

4. Ghafourian Boroujerdnia M, Khosravi N, Malek-Hosseini S, Amirghofran Z. Augmentation of lymphocytes activation and T cell modulation by the extracts from some Euphorbia species. Pharmaceutical biology. 2014 52(11):1471-7.

5. Amirghofran Z, Malek-hosseini S, Gholmoghaddam H, Kalalinia F. Inhibition of tumor cells growth and stimulation of lymphocytes by Euphorbia species. Immunopharmacol Immunotoxicol. 2011 33(1):34-42.

6. Ghanadian SM, Ayatollahi AM, Afsharypour S, Hareem S, Abdalla OM, Bankeu JJK. Flavonol glycosides from Euphorbia microsciadia Bioss. with their immunomodulatory activities. Iranian journal of pharmaceutical research: IJPR. 2012 11(3):925.

7. Baniadama S, Rahiminejad MR, Ghannadian M, Saeidi H, Ayatollahi AM, Aghaei M. Cycloartane Triterpenoids from Euphorbia macrostegia with their Cytotoxicity against MDAMB48 and MCF-7 Cancer Cell Lines. Iranian Journal of Pharmaceutical Research. 2014 13(1):135-41.

8. Demirkiran O, Topcu G, Azarpira A, Choudhary MI. Tyrosinase Inhibitory Activity of Chemical Constituents of Euphorbia macrostegia. Chemistry of Natural Compounds. 2014 50(5):8103.

9. Zare S, Ghaedi M, Miri R, Heiling S, Asadollahi M, Baldwin IT, et al. Phytochemical Investigation on Euphorbia macrostegia (Persian wood spurge). Iranian Journal of Pharmaceutical Research. 2015 14(1):243-9.

10. Mirzaei Y. Isolation and structural elucidation of natural products in Euphorbia erythradenia [MSc Thesis]. Yasouj: University of Yasouj; 2013.

11. Hashemi SS. Phytochemical investigation on the roots of Euphorbia microsciadia \& study of it's biological activities [MSc Thesis]. Yasouj: University of Yasouj; 2014.

12. Wagner $\mathrm{H}$, Bladt $\mathrm{S}$. Plant drug analysis: a thin layer chromatography atlas: Springer Science \& Business Media; 1996. 
13. Mosmann T. Rapid colorimetric assay for cellular growth and survival: application to proliferation and cytotoxicity assays. Journal of Immunological Methods. 1983 65(1):55-63.

14. Jassbi AR, Miri R, Asadollahi M, Javanmardi N, Firuzi O. Cytotoxic, antioxidant and antimicrobial effects of nine species of woundwort (Stachys) plants. Pharmaceutical Biology. 2014 52(1):62-7.

15. Jassbi AR, Singh P, Krishna V, Gupta PK, Tahara S. Antioxidant study and assignments of NMR spectral data for $3^{\prime}, 4^{\prime}, 7$ trihydroxyflavanone 3', 7-di-O- $\beta$-d-glucopyranoside (butrin) and its hydrolyzed product. Chemistry of Natural Compounds. 2004 40(3):250-3.

16. Firuzi O, Miri R, Asadollahi M, Eslami S, Jassbi AR. Cytotoxic, antioxidant and antimicrobial activities and phenolic contents of eleven Salvia species from Iran. Iranian journal of pharmaceutical research: IJPR. 2013 12(4):801.

17. Blois MS. Antioxidant Determinations by the Use of a Stable Free Radical. Nature. 1958 181(4617):1199-200.

18. Waterhouse AL. Determination of total phenolics. Current Protocols in Food Analytical Chemistry. 2002 6(1):11.1.1-.1.8.

19. Jassbi AR, Zamanizadehnajari S, Azar PA, Tahara S. Antibacterial diterpenoids from Astragalus brachystachys. Zeitschrift fur Naturforschung C-Journal of Biosciences. 2002 57(11-12):101621.

20. Benmerache A, Alabdul Magid A, Labed A, Kabouche A, Voutquenne-Nazabadioko L, Hubert $J$, et al. Isolation and characterisation of cytotoxic compounds from Euphorbia clementei Boiss. Natural product research. 2017 31(18):2091-8.

21. Ezzat SM, Choucry MA, Kandil ZA. Antibacterial, antioxidant, and topical anti-inflammatory activities of Bergia ammannioides: A wound-healing plant. Pharmaceutical biology. 2016 54(2):21524.

22. Hoskeri J, Krishna H, Jignesh V, Roshan S, Vijay S. In-silico drug designing using $\beta$-sitosterol isolated from Flaveria trinervia against peptide deformylase protein to hypothesize bactericidal effect. International Journal of Pharmacy and Pharmaceutical Sciences. 2012 4:192-6.

23. Shaker KH, Al Shehri BM, Oteef MDY, Mahmoud MF. Antioxidant compounds from Euphorbia schimperiana scheele in Aseer Region, Saudi Arabia. International Journal of Pharmaceutical Sciences Review and Research. 2015 32(1):11722.

24. Mali PY, Panchal SS. Euphorbia neriifolia L.: Review on botany, ethnomedicinal uses, phytochemistry and biological activities. Asian Pacific journal of tropical medicine. 2017 10(5):430-8 